BELDARRAÍN CHAPLE, Enrique. Una batalla ganada: la eliminación de la poliomielitis en Cuba. História, Ciências, Saúde - Manguinhos, Rio de Janeiro, v.22, n.3, jul.-set. 2015, p.961-983.

\title{
Una batalla ganada: la eliminación de la poliomielitis en Cuba
}

\section{A battle won: the elimination of poliomyelitis in Cuba}

\section{Enrique Beldarraín Chaple}

Profesor, Universidad Médica de La Habana; investigador, Grupo de Trabajo de Investigaciones/Centro Nacional de Información de Ciencias Médicas. Calle 29 No.159, entre C y D, Vedado. 10400 - La Habana - Cuba ebch@infomed.sld.cu

Resumen

La poliomielitis fue introducida en Cuba a finales del siglo XIX por norteamericanos residentes en Isla de Pinos. Las primeras epidemias ocurrieron en 1906 y 1909, aumentaron en intensidad entre 1930-1958. El objetivo del artículo es reconstruir la historia de la enfermedad y sus epidemias en Cuba hasta 1961, de la primera Campaña Nacional de Vacunación Antipolio (1962) y de sus resultados, bien como analizar la continuidad de las campañas anuales de vacunación hasta la certificación de su eliminación (1994). Se siguió el método histórico lógico; se revisaron documentos de archivos, las estadísticas del Ministerio de Salud Pública sobre morbilidad y mortalidad hasta el 2000. Se calcularon tasas brutas de morbilidad y mortalidad. Se realizaron entrevistas a personajes claves.

Palabras clave: poliomielitis; Cuba; vacunación; vacuna Sabin; historia.

Abstract

Poliomyelitis was introduced in Cuba in the late nineteenth century by American residents in Isla de Pinos. The first epidemics occurred in 1906 and 1909 and increased in intensity between 1930 and 1958. The scope of the paper is to reconstruct the history of the disease and its epidemics in Cuba prior to 1961, the first National Polio Vaccination Campaign (1962) and its results, as well as analyze the ongoing annual vaccination campaigns through to certified elimination of the disease (1994). The logical historical method was used and archival documents and statistics from the Ministry of Health on morbidity and mortality through 2000 were reviewed. Gross morbidity and mortality rates were calculated and interviews with key figures were conducted.

Keywords: poliomyelitis; Cuba; vaccination; Sabin vaccine; history. 
$\mathrm{L}$ a poliomielitis anterior aguda es una enfermedad viral que afecta principalmente a la población infantil y causa graves secuelas e invalidez. Se le conoció también como fiebre polio vírica, parálisis infantil y enfermedad de Heine-Medin. Existen tres formas de presentación de la infección: subclínica, no paralítica y paralítica. Aproximadamente el 95\% son infecciones subclínicas que pueden no tener síntomas. La infección subclínica se caracteriza por malestar general, cefaleas, enrojecimiento y dolor en la garganta, fiebre leve y puede haber vómitos, pero en muchos casos están ausentes. La poliomielitis clínica afecta al sistema nervioso central (el cerebro y la médula espinal) y se divide en las formas no paralítica y paralítica. La primera se caracteriza por dolores en la espalda, diarrea, cansancio excesivo, cefaleas, irritabilidad, dolor en las piernas (músculos de la pantorrilla), fiebre moderada, rigidez y sensibilidad muscular y espasmos en cualquier área del cuerpo, dolor y rigidez en el cuello y en la espalda, brazos, piernas y abdomen, erupción en la piel y vómitos, los que pueden durar hasta dos semanas. La paralítica se caracteriza por presencia de fiebre durante cinco a siete días antes que aparezcan otros síntomas, sensaciones anormales (pero sin pérdida de la sensibilidad) en un área, distensión abdominal, dificultad para respirar, estreñimiento, dificultad para comenzar a orinar, babeo, cefalea, irritabilidad, espasmos o contracciones musculares, particularmente en la pantorrilla, el cuello o la espalda, debilidad muscular asimétrica (solo en un lado o empeora en un lado) que aparece rápidamente, la localización depende de la parte en que la médula espinal esté afectada y que empeora la parálisis; sensibilidad al tacto, un toque leve puede ser doloroso; rigidez de nuca y espalda y dificultad para deglutir. La parálisis fláccida, aparece en menos del 1\% de las infecciones. El agente causal es el poliovirus (género Enterovirus), tipos 1, 2 y 3; todos pueden causar parálisis. La circulación de los poliovirus se limita a un número cada vez menor de países (Heymann, 2005).

Las epidemias producidas por la poliomielitis se conocieron a partir de 1890, cuando el pediatra Oskar Medin describió la historia natural de la poliomielitis aguda y sus complicaciones neurológicas durante una epidemia en Escandinavia. A raíz de eso, comenzó a llamarse enfermedad de Heine-Medin. Este carácter epidémico fue confirmado en 1907 por Vickmann. Tras ello se inició el estudio detenido del virus causal, con las experiencias en 1909 de Flexner, Lewis, Landsteiner y Popper de inoculación de suspensiones de médula espinal humana en monos que presentaron el cuadro típico de una parálisis fláccida, confirmando la transmisibilidad del proceso (Harries, Mitman, 1951).

Una epidemia de poliomielitis de gran magnitud que ocurrió en los EEUU en 1916 produjo seis mil defunciones y dejó secuelas paralíticas en 27 mil casos. La enfermedad constituyó un problema de salud en ese país y fue aumentando su incidencia; a principios de la década de 1950 había más de veinte mil casos de poliomielitis al año. En 1952, en plena epidemia de polio, se registraron casi sesenta mil casos con más de tres mil muertes. Como una medida de control de la enfermedad, se inició la vacunación contra la poliomielitis en 1955, vacunando a seis millones de niños menores de 15 años, con una respuesta profiláctica positiva. En el año 1960, el número de casos ya había disminuido a cerca de tres mil al año y en 1979 solo ocurrían cerca de diez casos al año. En los EEUU no se ha reportado ningún caso de poliomielitis aguda desde 1980. El éxito de la vacunación contra la poliomielitis en los EEUU y en otros países estimuló un esfuerzo mundial para eliminar esta enfermedad (US Department..., 2000). 
En Norteamérica, los últimos casos de la enfermedad causados por poliovirus salvaje fueron detectados en 1979 (US Department..., 2000). En la Argentina, desde el año 1984 no hay circulación de virus salvaje (Quadros, Hersh, Olivé, 1997).

En 1985, todos los países de América establecieron la meta de la eliminación regional del poliovirus salvaje para 1990 (CDC, 1994). En las Américas, el último caso de polio asociado con el aislamiento de poliovirus salvaje fue detectado en Perú en 1991 (CDC, 1993). La Región de las Américas fue certificada como libre de poliovirus salvaje en 1994, un logro conseguido fundamentalmente con el uso casi exclusivo de vacunas (Robbins, Quadros, 1997). La iniciativa global para la erradicación de la polio ha reducido el número de casos reportados mundialmente en más del 80\%, desde mediados de los años 1980, y tuvo como fin la erradicación mundial de la enfermedad para el 2000, hecho que aún no se ha conseguido, aunque parece una meta posible (PAHO, 12 abr. 2000).

\section{La poliomielitis en Cuba}

En Cuba se reportó la enfermedad por primera vez por el doctor Francisco Cabrera Saavedra al final de la dominación española, cuando encontró a personas con secuelas de la enfermedad en la ciudad de Caibarién, en 1898. Médicos norteamericanos observaron casos en el propio año, en Isla de Pinos (Martínez-Fortún, 1960). Sin embargo, fue en 1906 cuando se vio un pequeño brote en el pueblo de Santa Fe (Isla de Pinos), referido por el doctor Alberto Recio, pero sin dar a conocer los detalles (Recio, 1909).

Se supone que la enfermedad fue importada desde los EEUU por colonos residentes en esa isla, pues desde la segunda mitad del siglo XIX existió una fluida relación comercial entre Cuba y los EEUU. Un grupo numeroso de norteamericanos se instaló como colonos en la Isla de Pinos, fundando pueblos e importando sus costumbres. El primer día de 1899 se inició la primera intervención militar norteamericana en la isla que duró hasta el 20 de mayo de 1902 (Instituto..., 1998). Un gran contingente de tropas de ese país ocupó todo el territorio nacional, principalmente las ciudades de La Habana y Santiago de Cuba. Asimismo, a partir de 1906 y hasta 1909 ocurrió la segunda intervención militar norteamericana en el país; este movimiento de poblaciones norteamericanas en Cuba pudo haber facilitado la introducción de la enfermedad.

El doctor Alberto Recio, quien recogió los datos de la presencia de la enfermedad en 1906, reportó en 1909 tres casos de parálisis, producto de la poliomielitis, de los cuales dos eran de La Habana y uno de Calabazar (Recio, 1909). Ese mismo año se notificó la primera epidemia en la otrora provincia de Las Villas, que afectó principalmente a la ciudad de Santa Clara y algunos municipios con una incidencia de doscientos casos y 8\% de mortalidad (Martínez-Fortún, 1952) y 140 casos distribuidos en diez municipios, de acuerdo con un informe presentado por el doctor Recio al doctor Juan Guiteras, entonces director de sanidad (Beldarraín Chaple, 2005). En el informe constaba también que afectaba fundamentalmente a la población infantil menor de 4 años. Esta fue la primera epidemia que ocurrió en una población tropical, ya que las anteriores habían ocurrido en regiones no tropicales, como Europa y los EEUU.

A partir de entonces la enfermedad se hizo endémica, con un largo período de endemia baja. No hay estadísticas continuas de la enfermedad hasta 1932, por lo que no se puede establecer 
el número promedio de casos reportados ni época del año en que fueron más frecuentes. Se la clasifica epidemiológicamente como endemia baja, pues hubo casos, pero hasta 1934 no se reportaron epidemias en el país. Ese año se presentaron epidemias periódicas con una variabilidad estacional de cada cinco años aproximadamente (Martínez-Fortún, 1952).

En los años anteriores a la Revolución (1959) no existió en Cuba una política sanitaria que tuviera en cuenta medidas de profilaxis contra la poliomielitis, ni control alguno sobre la enfermedad (Beldarraín Chaple, 2005). Esta tenía un gran impacto social, además de ser un problema epidemiológico entre la población infantil cubana. Eran muy dramáticas las secuelas paralíticas y de deformidades neurolocomotoras que producía, además de su elevada mortalidad (Martínez-Fortún, 1952).

El presente trabajo tiene el propósito de describir la historia de la presencia de la poliomielitis anterior aguda en Cuba, desde que se diagnosticó por primera vez hasta su eliminación (1906-1962). Entre sus objetivos está rescatar los principales datos estadísticos de la morbilidad y mortalidad de la enfermedad en las epidemias presentadas, desde los inicios del siglo XX, explicar la campaña de vacunación que se inició en 1962 y su repercusión en la protección de la población infantil y el perfeccionamiento de las campañas de vacunación siguientes, que lograron la eliminación de la enfermedad en el país.

\section{Localización y manejo de la evidencia}

Para llevar a cabo la investigación se siguió el método histórico - lógico para el análisis documental (Hernández Sampieri, Fernández Collado, Baptista Lucio, 1996), apoyado en la heurística para realizar un análisis deductivo-inductivo de las fuentes disponibles sobre la historia general de la salud pública y la historia particular de la poliomielitis, y en la hermenéutica para arribar a consideraciones generales mediante un proceso de síntesis. Se realizaron entrevistas a actores que participaron en la primera campaña de vacunación contra la poliomielitis, entre ellos, el profesor Helenio Ferrer García, quien fue director de control de enfermedades transmisibles del Ministerio de Salud Pública (Minsap), desde 1961 hasta 1979, y uno de los organizadores de la Campaña Nacional de Vacunación antipoliomielítica. También a los profesores Conrado del Puerto Quintana, quién fuera subdirector provincial de salud en Matanzas, a cargo de la higiene y la epidemiología, entre los años 1961 y 1963 y a Gabriel Toledo Curbelo, médico que hacía el servicio social rural. Los dos eran jóvenes profesionales y participaron en las tareas de la primera campaña y de las siguientes; al doctor Miguel Ángel Galindo Sardiñas, responsable, durante muchos años, del Programa Nacional de Inmunizaciones del Minsap los cuatro, expertos en la historia de la epidemiología cubana. El universo de trabajo que abarcó el estudio estuvo conformado por las epidemias de poliomielitis ocurridas en Cuba en el período comprendido entre 1902 y 1962 y el diseño y puesta en marcha de la Campaña Nacional de Vacunación Antipoliomielítica, sus resultados y repercusiones. Se revisaron documentos de archivos, registros médicos, las estadísticas disponibles, existentes en la Dirección Nacional de Estadísticas del Ministerio de Salud Pública, sobre morbilidad y mortalidad por poliomielitis antes de 1959 y las posteriores hasta el 2000. Se calcularon tasas brutas de morbilidad y mortalidad, utilizándose las poblaciones estimadas a mitad de período, calculadas por el Comité Estatal de Estadísticas. Se revisaron informes y la literatura 
científica publicada sobre las campañas de vacunación antipoliomielítica y sus resultados. Se dispuso parte de la información en tablas y gráficos.

\section{Situación de la poliomielitis y cambios en la estrategia sanitaria cubana}

A pesar de que la notificación obligatoria de la enfermedad se estableció en Cuba en 1902, no todos los médicos cumplían con esta disposición. Fue realmente a partir de 1932 que existieron registros continuos de morbilidad y mortalidad (Tabla 1). Esta es la causa de la ausencia de epidemias registradas entre 1909 y 1934; tampoco se encontró en la bibliografía revisada ningún estudio relacionado con la presencia de la epidemia en alguna población cubana que no fuera la de 1909 en Santa Clara y alrededores (Martínez-Fortún, 1960).

Con los datos fidedignos, a partir de 1932 se pudieron registrar las cinco epidemias, entre este último año y 1958, que comenzaron a presentarse generalizadas a todo el país.

Así, la primera gran epidemia fue la de 1934-1935 con 613 casos y cien fallecidos; la del verano de 1942 al otoño de 1943, con 548 casos y 58 fallecidos; la de 1946-1947 que presentó 313 casos y 49 defunciones; la de 1952, con 492 casos y 15 defunciones y en 1955 con 277 casos y no se reportaron fallecidos (Martínez-Fortún, 1960) (Tabla 1).

De los datos encontrados se puede afirmar que la epidemia de 1946 se caracterizó por iniciarse en mayo, mes anterior a los meses en que las epidemias ocurrían normalmente. Se presentó desde la primavera, cuando habitualmente la poliomielitis era una enfermedad del verano, en los meses de julio y agosto. Coincidió con una epidemia que azotó a la Florida, EEUU. La diferencia fue que en Cuba afectó a la población menor de 5 años y en EEUU a la de 5-14 años de edad (Martínez-Fortún, 1960). Esta afectación en las edades más tempranas en Cuba puede que estuviera influenciada por las condiciones higiénicas y de saneamiento básico, pues en las ciudades más pequeñas y pueblos, en los barrios pobres y marginales - donde ocurrían la mayor cantidad de casos - las condiciones de vida no eran las mejores, había hacinamiento en las viviendas, muchas no tenían servicios sanitarios y utilizaban letrinas fuera de las mismas, había dificultades de acceso al agua potable, cierto estado de malnutrición entre los infantes, así como escasos niveles de protección a diferentes enfermedades inmunoprevenibles, lo que los convertía en grupos vulnerables no solo frente a la polio sino a cualquier enfermedad infectocontagiosa, pero esto no explica totalmente la diferencia de los grupos de edades atacados en los dos países durante esta epidemia. Desde entonces mantuvo un carácter endemo - epidémico con brotes de intensidad variable, que ocurrían a intervalos de cuatro a siete años. Los porcentajes reportados de casos mayores de 10 años de edad se incrementaron en las epidemias siguientes; así, del 3\% en 1934 pasó al $14 \%$ en 1946.

A partir de 1959, con la obligatoriedad del reporte de las enfermedades, las estadísticas fueron más completas y se pudieron obtener los datos de los casos ocurridos por meses, comprobándose que los de mayores reportes fueron los meses de verano (junio a agosto) y se observó un aumento de casos por año (Tabla 2). De 1957 a 1961 la enfermedad volvió a presentar un carácter endemo-epidémico; cifras tan elevadas como en años de epidemias, ya señalados en las dos décadas anteriores, se han interpretado como una mejora notable en el reporte de los casos que fue celosamente observado en todas las unidades médicas 
del país, aunque sí se consideró como el último brote epidémico, el que se produjo en 1961, y del cual se reportaron 342 casos (Tabla 1), el 30\% en mayores de 4 años (Gráfico 1) (Beldarraín, 2005).

Tabla 1: Incidencia y mortalidad anual de poliomielitis en Cuba, 1932-1961

\begin{tabular}{|c|c|c|c|c|}
\hline Año & $\begin{array}{l}\text { No. de } \\
\text { casos }\end{array}$ & $\begin{array}{l}\text { Tasa incidencia } \\
\text { x } 100 \text { mil hab. }\end{array}$ & Fallecidos & $\begin{array}{l}\text { Tasa mortalidad } \\
\text { x } 100 \text { mil hab.* }\end{array}$ \\
\hline 1932 & 8 & 0,2 & - & - \\
\hline 1933 & 5 & 0,1 & - & - \\
\hline 1934 & 434 & $10,5^{* *}$ & 81 & 1,95 \\
\hline 1935 & 179 & 4,3 & 19 & 0,45 \\
\hline 1936 & 81 & 1,9 & - & - \\
\hline 1937 & 70 & 1,6 & - & - \\
\hline 1938 & 29 & 0,7 & - & - \\
\hline 1939 & 67 & 1,5 & - & - \\
\hline 1940 & 25 & 0,5 & - & - \\
\hline 1941 & 16 & 0,4 & - & - \\
\hline 1942 & 494 & 10,6 & 58 & 1,23 \\
\hline 1943 & 54 & 1,1 & - & - \\
\hline 1944 & 33 & 0,7 & - & - \\
\hline 1945 & 9 & 0,2 & - & - \\
\hline 1946 & 239 & 4,9 & 33 & 0,64 \\
\hline 1947 & 74 & 1,4 & 16 & 0,30 \\
\hline 1948 & 4 & 0,1 & - & - \\
\hline 1949 & 28 & 0,5 & - & - \\
\hline 1950 & 28 & 0,5 & - & - \\
\hline 1951 & 11 & 0,2 & - & - \\
\hline 1952 & 492 & 8,6 & 15 & 0,26 \\
\hline 1953 & 68 & 1,2 & - & - \\
\hline 1954 & 56 & 0,9 & - & - \\
\hline 1955 & 267 & 4,4 & - & - \\
\hline 1956 & 6 & 0,9 & - & - \\
\hline 1957 & 98 & 1,5 & - & - \\
\hline 1958 & 104 & 1,6 & - & - \\
\hline 1959 & 288 & 4,3 & - & - \\
\hline 1960 & 330 & 4,9 & - & - \\
\hline 1961 & 342 & 4,9 & - & - \\
\hline Total & 3939 & - & 238 & - \\
\hline
\end{tabular}

*Tasas de mortalidad por cien mil habitantes (calculadas por el autor).

**Se destacan en negrita los años epidémicos. Los años 1934 y 1935, se consideran una sola epidemia.

***Las cifras de los años 1959-1961, a pesar de ser tan elevadas, no se consideraron epidémicos, pues se relacionaron con el cumplimiento estricto de la notificación obligatoria.

Fuente: Cuba, s.d. 
Tabla 2: Casos de poliomielitis según mes y año en Cuba, 1959-1961

\begin{tabular}{rrrrrrrrrrrrrr}
\hline Año & Ene. & Feb. & Mar. & Abr. & Mayo & Jun. & Jul. & Ago. & Sep. & Oct. & Nov. & Dic. & Total \\
\hline 1959 & 18 & 33 & 31 & 37 & 24 & 59 & 29 & 26 & 14 & 9 & 4 & 4 & 288 \\
1960 & 3 & 9 & 16 & 10 & 27 & 44 & 54 & 49 & 50 & 26 & 23 & 19 & 330 \\
1961 & 22 & 31 & 36 & 32 & 22 & 54 & 35 & 30 & 17 & 27 & 18 & 18 & 342 \\
\hline Total & 43 & $\mathbf{7 3}$ & $\mathbf{8 3}$ & $\mathbf{7 9}$ & $\mathbf{7 3}$ & $\mathbf{1 5 7}$ & $\mathbf{1 1 8}$ & $\mathbf{1 0 5}$ & $\mathbf{8 1}$ & $\mathbf{6 2}$ & $\mathbf{4 5}$ & $\mathbf{4 1}$ & $\mathbf{9 6 0}$ \\
\hline
\end{tabular}

Fuente: Cuba, s.d.

Gráfico 1: Incidencia de poliomielitis (tasas x 100 mil habitantes) en Cuba, 1932-1961

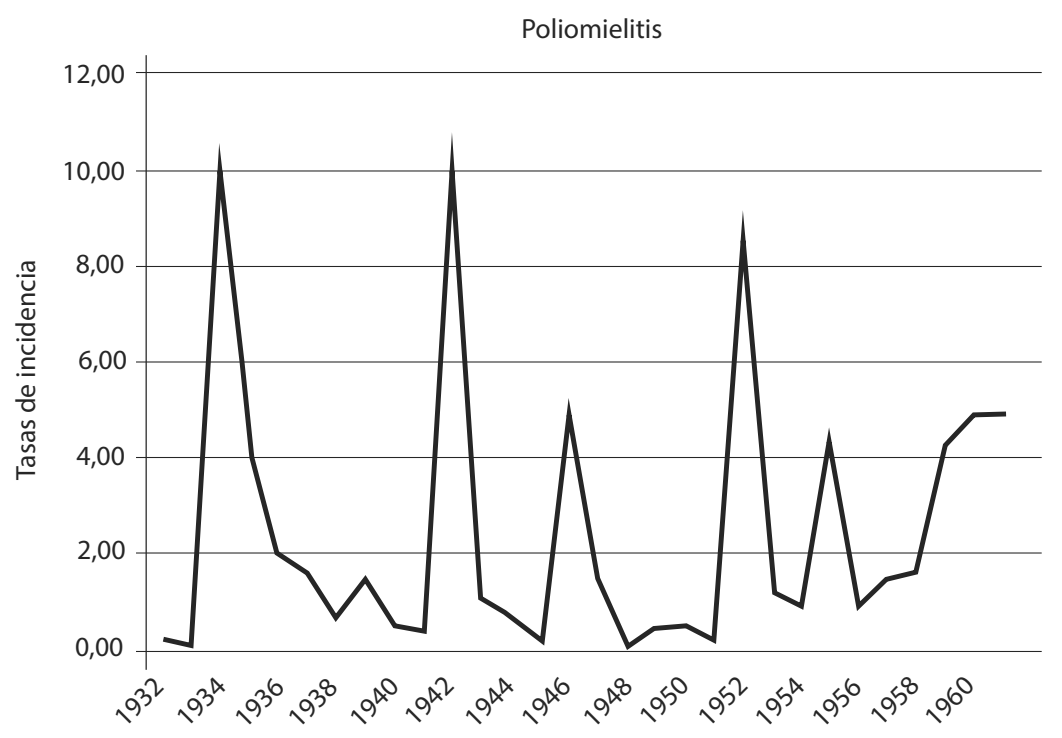

Fuente: Tabla 1.

Una de las primeras medidas que tomó entonces el Minsap para lograr la eliminación de esta terrible enfermedad fue la realización de una campaña masiva de vacunación de toda la población infantil del país, con el uso de la vacuna Sabin oral trivalente, de eficacia probada, inocua y de fácil administración (Vacunación..., 1962).

Previo a la planificación de la campaña, se evaluaron las investigaciones epidemiológicas existentes sobre la poliomielitis en el país y se realizaron otros estudios sobre la historia de la evolución y las características de la enfermedad en los treinta años anteriores, que ratificaron lo que se ha expuesto en los párrafos anteriores (Beldarraín Chaple, 2005). Entre 1932 y 1961 se notificaron 3.939 casos de poliomielitis (Tabla 1). De ellos, 3.134 paralíticos, de los cuales ocurrieron 430 defunciones, con una letalidad general de 10,9\% (Vacunación..., 1962).

Para comprender el diseño de la primera Campaña Nacional de Vacunación Antipoliomielítica realizada en Cuba, que fue además una estrategia de intervención en la lucha contra la enfermedad, es necesario relacionar una serie de sucesos que a nivel nacional, político y administrativo propiciaron estas acciones, que empelaron nuevas visiones de la salud, de la estrategia de trabajo del sector, así como su orientación hacia la prevención de la salud de la comunidad. 
La salud pública cubana en la etapa anterior al triunfo revolucionario (hasta 1958) siempre estuvo dirigida hacia la curación de las enfermedades y no se estableció una verdadera política dirigida a la protección de la población contra las alteraciones del proceso salud-enfermedad. Existía la asistencia sanitaria pública, pero estaba limitada a las grandes poblaciones, con escasa presencia en las áreas rurales y una gran manifestación de la medicina privada y de la mutualista, representada fundamentalmente por las Quintas de Salud, pertenecientes a las sociedades regionales españolas que disponían de excelentes dependencias y facilidades, donde se brindaba una atención médica de alta calidad. Pero todas estas variedades de atención estaban dirigidas a la medicina curativa: la curación individual de los pacientes. Aunque existía un trabajo sanitario dirigido por el Departamento Nacional de Sanidad y un médico sanitarista en los principales municipios de la nación, su trabajo era más localizado hacia las epidemias puntuales que se presentaban que a la profilaxis de las enfermedades (Beldarraín Chaple, 2007; Rojas Ochoa, López Serrano, 2002).

Después de 1959, una de las transformaciones fundamentales en el aspecto sanitario, introducidas por la Revolución, fue el cambio de orientación, de todo el sistema, hacia la prevención de las enfermedades y la promoción de la salud, lo que conllevó el diseño de una nueva estrategia sanitaria a nivel nacional y la transición de las mentalidades de los profesionales de la salud, acompañada de un cambio cualitativo del enfoque de los estudios de medicina en la única universidad en que ésta se enseñaba en esos momentos: la Escuela de Medicina de la Universidad de La Habana (Beldarraín Chaple, 2005).

Entre los cambios principales que ocurrieron en el año 1959, se puede mencionar, el 5 de enero, el nombramiento como ministro de Salubridad y Asistencia Social al doctor Julio Martínez Páez, comandante y jefe de los servicios médicos del Ejército Rebelde, quien iniciaría la nueva visión de la salud que tenían los revolucionarios y que ya habían practicado en la Sierra Maestra, brindando atención médica a la población de la zona y haciendo trabajo profiláctico con las mismas. Un mes más tarde se cambió el nombre del ministerio por el de Salubridad y Asistencia Hospitalaria. A partir de estos momentos se inició el cambio en la orientación del desempeño de la salud pública cubana: el enfoque dirigido a la medicina preventiva, a la profilaxis de enfermedades. Las primeras actividades fueron la preparación de las primeras campañas sanitarias, se firmaron convenios con la Organización Panamericana de la Salud (OPS) para la ejecución de los programas de erradicación del paludismo y del control del mosquito Anopheles (Beldarraín Chaple, 2005; Del Puerto, Ferrer, Toledo, 2002; Delgado, 1991; Rojas Ochoa, López Serrano, 2002).

En enero de 1960 se promulgó la ley 717, que cambió el nombre de Ministerio de Salubridad y Asistencia Hospitalaria por el de Ministerio de Salud Pública (Minsap) y se creó el Servicio Médico Social Rural, medida trascendental mediante la cual se llevó la asistencia médica a lugares remotos del territorio nacional donde nunca habían tenido asistencia profesional. Se creó la Cruz Roja Rural y, en mayo, se nombró ministro al comandante, doctor José Ramón Machado Ventura. Siguieron las Unidades Sanitarias, primer intento de crear una unidad básica de atención primaria en las zonas urbanas que a nivel municipal integraban a la Organización Nacional para el Desarrollo de la Infancia, el Patronato de la Lepra, las jefaturas municipales de sanidad y las antiguas Casas de Socorro. También se crearon las Columnas Sanitarias que en número de tres recorrían el país y realizaban actividades de saneamiento ambiental, 
vacunación y educación sanitaria. Las actividades de educación sanitaria comenzaron a transformar los hábitos higiénicos de la población campesina y la integración a las acciones preventivas de salud como la vacunación de los niños, los partos institucionales y la lucha contra el mosquito en la campaña de erradicación del paludismo. Se desarrolló la participación social comunitaria en los eventos de salud a través de las Brigadas Sanitarias de la Federación de Mujeres Cubanas y de los responsables de salud en sindicatos y organizaciones de masas (Beldarraín Chaple, 2005; Del Puerto, Ferrer, Toledo, 2002; Delgado, 1991).

Durante el mes de agosto de 1961 se inició, de forma experimental, el trabajo de los policlínicos y en ese mismo mes se promulgaron la ley 958, por la cual se extinguió el Ministerio de Bienestar Social y se incorporaron sus unidades al Minsap, y la ley 959, que estableció que el Minsap era el organismo rector de las actividades de salud y precisó el carácter socialista de la salud pública.

En los primeros días de 1962 se creó la subsecretaría de Higiene y Epidemiología. Por primera vez el ministerio contó con una gran sección encargada de dichas tareas y a partir de estos momentos se inició el verdadero desarrollo de esta rama de las ciencias médicas, con la formación postgraduada de especialistas y el inicio de una red en todo el país que se ocuparía de su progreso a nivel local, extendiéndose en los próximos años por todo el país y constituyendo posteriormente los Centros Provinciales de Higiene y Epidemiología y los Centros y Unidades Municipales de Higiene y Epidemiología, a los cuales se les anexó la red de laboratorios de microbiología, tan importantes para el trabajo de esta esfera. Recién iniciado el trabajo del Departamento Nacional de Epidemiología, la dirección del ministerio elaboró las Metas Generales para la Realización del Plan de Salud Pública de 1962 a 1965. Este plan fue una guía de trabajo que precisó 15 tareas fundamentales para el desarrollo, entre las cuales se incluían: disminuir la mortalidad en el niño, principalmente en la primera infancia, un amplio plan de vacunación, lucha contra la difteria con una campaña de vacunación masiva en edades pediátricas, al igual que con la vacuna BCG para luchar contra la tuberculosis infantil y la poliomielitis (Beldarraín, 2005; Del Puerto, Ferrer, Toledo, 2002; Delgado, 1991).

En septiembre del propio año 1962 se celebró el primero Forum Nacional de Higiene y Epidemiología, que fue un evento científico y, a la vez, una reunión metodológica de trascendental importancia para el desarrollo de la especialidad. Se discutieron científicamente todos los aspectos a desarrollar para el control de las enfermedades transmisibles que ocasionaban una morbilidad elevada en el país. Se enunciaron y discutieron los principales programas de control puestos en marcha inmediatamente, las campañas epidemiológicas a desarrollar en seguida y los resultados alcanzados hasta ese momento por las que ya habían iniciado sus actividades. En resumen, se diseñó la estrategia de trabajo de la higiene y epidemiología para los próximos diez años en el país (Beldarraín Chaple, 2005).

\section{La vacunacion contra la poliomielitis}

Con la nueva estrategia de trabajo adoptada por la salud pública cubana y la situación existente en relación a la poliomielitis y la sensibilidad social que sus afectaciones provocaban, sumado a la posibilidad que brindaba la existencia de una vacuna eficaz, segura y fácil de aplicar motivó que las autoridades sanitarias del país tomaran la decisión de controlar la 
enfermedad mediante una campaña de vacunación. En la segunda mitad del año 1961, la Dirección Nacional de Epidemiología contó con la asesoría científico técnica del doctor Karel Sacek, jefe de Epidemiología y Microbiología de Checoslovaquia y miembro del comité de expertos en virología de la OMS, quién realizó estudios epidemiológicos sobre el comportamiento de la poliomielitis en Cuba, la época del año en que se presentaba con mayor frecuencia y los grupos de edades más vulnerables. Los resultados arrojaron que la incidencia de casos era mayor en los meses de verano, entre junio y agosto, y atacaba, fundamentalmente, a niños menores de 4 años, aunque estaban en riesgo todos los menores de 15 . De acuerdo a estos resultados, se decidió vacunar en los meses previos al inicio del verano y en las edades comprendidas desde un mes del nacimiento hasta los 15 años (Ferrer, jun. 2008).

La estrategia aplicada se basó en tres elementos esenciales: (1) lograr altas coberturas de vacunación mediante campañas de una semana de duración para cada una de las dos dosis a aplicar, antes de los meses de verano; (2) vigilancia de los casos sospechosos; (3) acciones de control de foco, de ser necesario (Vacunación..., 1962).

Después de tener bien delimitado el problema y la evidencia científica de que con las posibilidades materiales disponibles y con el cambio de paradigma que introdujo la medicina revolucionaria, con los nuevos profesionales integrantes del servicio médico social rural y con la creación de los puestos médicos rurales que dotaron de una infraestructura para el trabajo, se hacía realizable el sueño de la eliminación de la enfermedad y se procedió a la planificación de la estrategia a seguir para conseguirlo. Esta nueva estructura sanitaria y la existencia de las organizaciones de masas en todo el territorio nacional constituyeron fortalezas para impulsar la vacunación antipoliomielítica en forma de campaña (Beldarraín Chaple, 2005).

Se planeó vacunar con la vacuna Sabin oral trivalente, al 80\% de la población infantil entre un mes y 14 años de edad. En toda la nación, sumando un total de 1.999.785 niños (Ferrer, Más Lago, 1967). Las fases de la primera campaña nacional de vacunación realizada se resumen en la Tabla 3 (Vacunación..., 1962).

Tabla 3: Cronograma de las actividades de la primera Campaña de Vacunación Antipoliomielítica

\begin{tabular}{|c|c|c|}
\hline Actividad & Fecha & Total de tiempo \\
\hline Planificación de la campaña & $\begin{array}{l}\text { Finales de diciembre de } 1961 \\
\text { a } 25 \text { de febrero de } 1962\end{array}$ & 2 meses \\
\hline $\begin{array}{l}\text { 1a Fase de la campaña Aplicación } \\
\text { de la primera dosis }\end{array}$ & $\begin{array}{l}26 \text { de febrero de } 1962 \text { al } \\
4 \text { de marzo de } 1962\end{array}$ & 1 semana (7 días) \\
\hline Período entre fases & $\begin{array}{l}14 \text { de marzo de } 1962 \text { a } \\
24 \text { de abril de } 1962\end{array}$ & 4 semanas ( 28 días) \\
\hline $\begin{array}{l}2^{\text {a }} \text { Fase de la campaña Aplicación } \\
\text { de la segunda dosis }\end{array}$ & $\begin{array}{l}25 \text { de abril de } 1962 \text { al } \\
1^{\circ} \text { de mayo de } 1962\end{array}$ & 1 semana (7 días) \\
\hline Evaluación & Mayo 1962 & 2 semanas \\
\hline Total & $\begin{array}{l}\text { Diciembre de } 1961 \text { al } \\
15 \text { de mayo de } 1962\end{array}$ & 6 meses \\
\hline
\end{tabular}

Fuente: Elaborado por el autor con datos de Del Puerto, Ferrer, Toledo (2002); Vacunación... (1962); Ferrer (jun. 2008). 


\section{La organización de la campaña}

La campaña estuvo bajo la dirección y supervisión del Minsap con la colaboración de las organizaciones de masas. Se constituyó una Comisión Nacional Coordinadora, integrada por el subsecretario de Higiene y Epidemiología, el subsecretario de Asistencia Médica, el presidente del Colegio Médico Nacional, el presidente de la Cruz Roja y representantes de las organizaciones de masas: los Comités de Defensa de la Revolución (CDR, personas y vecinos organizados por cuadras), la Federación de Mujeres Cubanas (FMC, mujeres que voluntariamente querían participar en el nuevo proyecto social), la Asociación de Jóvenes Rebeldes (AJR) y la Asociación Nacional de Agricultores Pequeños (Anap). La tarea fundamental de esas organizaciones fue incorporar a la población a las actividades de la campaña, ayudar en la creación de la conciencia popular, eliminar las posibles reticencias de las familias a la vacunación (sobre todo entre la población campesina) y garantizar la adecuada afluencia de la población infantil a los puntos de vacunación (Vacunación..., 1962).

La Comisión Nacional de Vacunación Antipolio, que tuvo un carácter gerencial técnico normativo, la integraron funcionarios de las Subsecretarías de Higiene y Epidemiología y de Asistencia Médica y contó, como ya se dijo, con el asesoramiento directo del doctor Karel Sacek, jefe de Epidemiología y Microbiología de Checoslovaquia y miembro del Comité de Expertos en Virología de la OMS (Más Lago et al., 1994; Ochoa, Más Lago, 1987).

Entre los dirigentes de la sección científico técnica de la campaña participaron el doctor Heliodoro Martínez Junco, subsecretario de Higiene y Epidemiología, como presidente de la Comisión de la Campaña; los doctores Mario Escalona, subsecretario del Minsap y José R. Balaguer, director general ejecutivo del ministerio; Helenio Ferrer, director de Control de Enfermedades Transmisibles y los especialistas de la referida dirección, Cosme Ordóñez, Antonio Moreno de Luna, Antonio Palacín, René Crucet, José M. Miyar, Gerald Simón y José M. Rodríguez.

A nivel de cada dirección regional (estructura territorial-administrativa que correspondía a cada provincia, excepto para la otrora provincia de Oriente que estaba dividida en dos direcciones regionales; en total fueron siete en el país, pues había seis provincias) existió una comisión con funciones de coordinación y control de la labor que se realizaba en las distintas unidades ejecutoras y del almacenamiento y distribución de la vacuna. La integraron el director regional de Salud Pública, los responsables de Higiene y Epidemiología, Asistencia Médica, del programa de Atención a la Mujer y el Niño, del Consejo Provincial de Educación y los responsables regionales de las organizaciones de masas (Vacunación..., 1962).

En cada una de las direcciones zonales (otra estructura territorial-administrativa en que se dividieron las direcciones regionales; eran correspondientes a un municipio) funcionó una comisión zonal que se responsabilizó por la coordinación y ejecución de la vacunación a ese nivel, al que se adjudicaron las cantidades necesarias de equipos fijos y móviles. Estas comisiones estaban integradas por el director zonal de Salud Pública, los responsables de Higiene y Epidemiología, Asistencia Médica, representantes de las Organizaciones Revolucionarias Integradas, el Consejo Municipal de Educación y las organizaciones de masas (Vacunación..., 1962).

En la vacunación de la población rural tuvieron especial responsabilidad el Servicio Médico Social Rural, las milicias campesinas y la Anap. 
Las fuerzas que enfrentaron el trabajo de esta campaña estaban divididas en "equipos fijos" y "equipos móviles". Los primeros correspondían a los centros de vacunación (ubicados en instalaciones previamente seleccionadas en centros de salud y escuelas, principalmente) y estaban constituidos por un médico que dirigía el centro, un responsable de vacuna, que tenía a su cargo el transporte y administración de la misma, auxiliado por dos personas más: un responsable de estadística para la revisión y control de las tarjetas de vacunación y confección de las listas de vacunados, del modelo de información diaria, que se entregaba a la dirección zonal, la entrega de comprobantes y de los carnets de vacunación a la población y los responsables de orden, que eran entre cinco y diez personas, que cuidaban el orden y vigilaban el proceso de ingestión total del caramelo vacuna. Los segundos, los móviles, se desplazaban a lugares más distantes para efectuar las tareas de administración de la vacuna y su control estadístico; este desplazamiento podía ser por medio automotor (jeeps, microbuses etc.) o por caballos o mulos en áreas rurales de difícil acceso y los integraban cinco personas: el responsable de equipos, el responsable de vacunas, el responsable de estadísticas más dos responsables de orden (Vacunación..., 1962). Ambos equipos tenían la función de control y administración de la vacuna a la población infantil. El trabajo de ambos grupos era coordinado por las comisiones zonales de vacunación antipoliomielítica.

El Ministerio de Educación aportó los locales escolares, que sirvieron de centros de vacunación, así como los maestros, que participaron como miembros de los equipos de vacunación. El Ministerio de las Fuerzas Armadas Revolucionarias facilitó helicópteros para el transporte de las vacunas y de personal en las regiones montañosas y zonas de más difícil acceso. El Instituto Nacional de la Reforma Agraria puso a disposición de la campaña los vehículos refrigerados.

Los CDR, la FMC, la Cruz Roja Cubana, la AJR y la Anap tuvieron la responsabilidad de cumplimentar coordinadamente las tareas siguientes:

- participación en las comisiones en los distintos niveles;

- colaboración activa en la propaganda de la vacunación y en la creación de la conciencia popular sobre la conveniencia de la campaña;

- movilización de los niños hacia los centros de vacunación;

- constitución de las comisiones de orden, confección de los datos estadísticos y relación de otras actividades para el mejor desenvolvimiento de la vacunación masiva;

- control de los niños no vacunados durante el período de vacunación nacional;

- el control de las tarjetas de vacunación donde recolectaron todos los datos necesarios y ofrecieron toda clase de explicaciones a las madres para que conocieran de la necesidad de llevar las tarjetas al Centro de Vacunación (Vacunación..., 1962).

\section{Preparación de los recursos humanos}

Esta fue una tarea de primordial importancia que hubo que acometer antes de iniciar la campaña, pues la misma involucraría a una cantidad extraordinaria de personas, profesionales, técnicos y personal no calificado de la población general. Los profesionales necesitaban conocimientos técnicos recientes acerca de la enfermedad, la vacuna, las estrategias de una 
campaña, las técnicas sobre las formas de aplicación y, todos, sobre las actividades de educación para la salud a realizar en todas las zonas y comunidades.

A escala nacional y en las diferentes regiones, el profesor Karel Zacek dictó conferencias referentes a la poliomielitis y a la vacuna oral con virus vivo, dirigidas a los profesionales y a los directores zonales; los profesionales nacionales adiestraron al personal auxiliar, compuesto por vacunadores, brigadistas sanitarios y responsables de salud de las organizaciones de masas a nivel regional y zonal. A nivel nacional y regional, se realizaron cursillos de cinco días de duración sobre vacunación, en especial sobre vacunación antipoliomielítica oral, para tres mil instructores responsables de salud, los que a su vez instruyeron a cincuenta mil responsables de salud de las organizaciones de masas (Vacunación..., 1962).

\section{Estrategia de divulgación a la población}

Era necesario garantizar el apoyo de la población a esta campaña, lo que se podía alcanzar con las actividades de educación sanitaria que se haría a escala local en cada zona del país, pero para apoyar esta tarea y potenciarla antes del inicio de la vacunación se desarrolló una intensa campaña de divulgación y educación sanitaria que incluyó la emisión, por radio y televisión, de mensajes en número y frecuencia suficientes, con un mínimo de treinta mil antes y durante las etapas de ejecución de la campaña. También salió al aire un programa radial diario dramatizado, dirigido a la población campesina, con una duración de treinta minutos y espacios de 12 minutos diarios en televisión con charlas, dramatizaciones, conferencias e instrucciones referentes a la vacunación antipoliomielítica. Se efectuaron cuatro mesas redondas por televisión, dos de carácter técnico y dos de divulgación popular, en las que participaron los responsables nacionales de la campaña (Vacunación..., 1962; Beldarraín Chaple, 2005).

En las mesas redondas televisadas intervinieron los doctores Heliodoro Martínez Junco, Mario Escalona, José Ramón Balaguer, Helenio Ferrer, Cosme Ordóñez, Antonio Moreno de Luna, Antonio Palacín, René Crucet, José M. Miyar, Gerald Simón y José M. Rodríguez, especialistas de la Comisión Nacional de la Campaña de Vacunación Antipoliomielítica.

En las diferentes zonas se informó al público, mediante unidades móviles del Departamento de Educación para la Salud del Minsap y se distribuyeron afiches por todo el país, dirigidos a la población en general y a las madres, los campesinos y los niños. Además, se hizo una intensa campaña de prensa en periódicos, revistas, boletines y vallas divulgativas en ciudades y pueblos. Una vez iniciada la campaña, los datos sobre el estado de la vacunación se divulgaban diariamente para el conocimiento de todo el país (Vacunación..., 1962).

\section{La vacuna}

Se utilizó la vacuna Sabin oral trivalente (serogrupos 1, 2 y 3), de virus vivo atenuado, que contenía un millón de DICT $_{50}$ (dosis infectantes medias por cultivo de tejidos), ${ }^{1}$ divididas en quinientos mil, doscientos mil y trescientos mil para los serogrupos 1, 2 y 3 respectivamente, con presentación en forma de gragea o caramelo, de producción soviética. El total de dosis empleadas fue de cinco millones (Más Lago et al., 1994). 
La obtención de todas las dosis necesarias para la inmunización de la población planificada se coordinó con el Ministerio de Salud Pública de la antigua URSS, que las hizo llegar en dos envíos, en correspondencia con cada etapa planeada de la campaña. Se transportaron y almacenaron a -20C (Vacunación..., 1962; Ferrer, Más Lago, 1967; Ochoa, Más Lago, 1987).

En cada una de las etapas se prepararon 330 mil dosis de vacuna líquida que se administraron a niños menores de 2 años. En el Instituto Nacional de Higiene, Microbiología y Epidemiología se realizó la dilución de los caramelos vacunas para formar, con la adición de agua destilada, una suspensión homogénea estable, de $\mathrm{pH}$ 7,2 que se envasó en frascos previamente esterilizados de $120 \mathrm{ml}$ de capacidad. Cada frasco contenía una cantidad de la suspensión equivalente a 44 dosis de 2,5ml de vacuna (Ferrer, Más Lago, 1967; Más Lago et al., 1994; Ochoa, Más Lago, 1987).

La vacuna se distribuyó, por medio de vehículos refrigerados, del almacén central a las siete comisiones regionales y se mantuvo en frigoríficos apropiados, a temperatura de $-20^{\circ} \mathrm{C}$. De las comisiones regionales se transportó a las direcciones zonales en transportes refrigerados mantenidos entre 4 y $8^{\circ} \mathrm{C}$. De allí se distribuyeron las dosis en neveras portátiles a los centros de vacunación por los medios de transporte que resultaban más apropiados, protegidas por una cubierta de nylon para evitar la acción de la humedad (Ochoa, Más Lago, 1987).

\section{Vacunación}

Se vacunó a la población infantil según lo programado (Tabla 4) con la administración de 2,5ml de suspensión a los niños menores de 2 años y por medio del caramelo vacuna a los comprendidos entre 2 y 14 años. La suspensión fue administrada con cucharillas y el caramelo vacuna fue tomado directamente por los niños (Vacunación..., 1962).

Para el control y registro de las dosis se imprimieron tarjetas de vacunación individual con los datos de identificación de cada niño, su lugar de domicilio, la fecha de administración, las dosis y la firma del responsable de vacunación.

Los responsables de salud de los CDR y los miembros de la Anap procedieron a registrar, en los carnets o tarjetas de vacunación, a todos los niños desde 1 mes hasta los 14 años, tanto de los sectores urbanos como de los rurales. La tarjeta se dejó en poder de los familiares para que pudieran presentarla en cada Centro de Vacunación, donde quedaron archivadas por orden alfabético después de finalizar la primera etapa, de manera de poder utilizarlas

Tabla 4: Vacunación antipoliomielítica oral en Cuba, rendimiento del programa y niveles alcanzados en la población por grupos de edades, 1962

\begin{tabular}{lccccc}
\hline $\begin{array}{l}\text { Grupos } \\
\text { Edades }\end{array}$ & $\begin{array}{l}\text { Población } \\
\text { (30 de junio) }\end{array}$ & $\begin{array}{l}\text { Programados } \\
\text { a vacunar }\end{array}$ & $\begin{array}{l}\text { Vacunados (con } \\
\text { las dos dosis) }\end{array}$ & \% Población & \% Programado \\
\hline 1-11 meses & 202.685 & 162.143 & 193.912 & 95,7 & 119,6 \\
1-5 años & 942.242 & 753.790 & 754.858 & 80,1 & 100,1 \\
6-14 años & 1.354 .805 & 1.083 .842 & 1.239 .085 & 91,4 & 114,3 \\
\hline Total & $\mathbf{2 . 4 9 9 . 7 3 2}$ & $\mathbf{1 . 9 9 9 . 7 5 8}$ & $\mathbf{2 . 1 8 7 . 8 5 5 *}$ & $\mathbf{8 7 , 5}$ & $\mathbf{1 0 9 , 4}$ \\
\hline
\end{tabular}

*No se incluyen 32.052 vacunados no clasificados por edades.

Fuente: Datos del Departamento de Estadística del Minsap (Vacunación..., 1962). 
durante la administración de la segunda dosis a cada niño (Vacunación..., 1962). Se expidió un comprobante de vacunación para dejar constancia a las familias que habían vacunado a sus niños, y poder mostrarlo a los representantes de las organizaciones de masas y personal sanitario en sus vistas de terreno mientras el carnet permanecía en lugar de vacunación.

El carnet de vacunación utilizado por los centros de vacunación se completó al recibir la segunda dosis. Este sirvió además de modelo oficial para la anotación conjunta de los diferentes tipos de vacunas.

\section{Reportes y evaluación de las actividades de la campaña de vacunación}

La evaluación de las actividades de la campaña se hizo simultáneamente con su desarrollo diario, de acuerdo con los resúmenes en los tres niveles de organización: nacional, regional y zonal. Se efectuó la tabulación mecánica de las tarjetas como evaluación final, donde se especificó la distribución por grupos de edad, número de dosis alcanzadas en cada nivel y el porcentaje representado en el objetivo fijado previamente. Con ello se precisaron los resultados en el nivel nacional y en los niveles regionales y zonales (Vacunación..., 1962; Ferrer, Más Lago, 1967).

La información diaria de los centros de vacunación expresaba la distribución por grupos de edad y las cantidades de dosis líquidas y caramelos empleados.

Se elaboraban resúmenes diarios a nivel zonal, que se transmitían por vía telefónica a la Dirección Regional. A nivel regional, los datos del Modelo de Resumen de Vacunación se hacían llegar diariamente, por teléfono, al Departamento de Estadísticas del Minsap (Vacunación..., 1962; Ferrer, Más Lago, 1967).

El resumen a nivel nacional se totalizó diariamente con los datos aportados por los tres niveles, para evaluar el desarrollo de la campaña y mantener a la población debidamente informada.

\section{Evaluación general de la campaña de vacunación}

Se realizó una evaluación cualitativa del resultado de la vacunación que incluyó la evaluación del estado inmunológico alcanzado en la población infantil. Esta se efectuó mediante la titulación de los anticuerpos neutralizantes existentes en el suero sanguíneo, antes y después de cada una de las etapas de la campaña, procedimiento estándar para la determinación de la inmunidad a los polio virus, usándose específicamente la prueba de la micro aglutinación (Tejas et al., mayo 1994). Para la evaluación se utilizaron 476 muestras de sueros procedentes de todo el país antes de iniciarse la primera campaña de vacunación y a las cuatro semanas de concluida la primera etapa, con 433 muestras. Este control serológico se repitió seis meses después de finalizada la segunda etapa. El resultado demostró una baja protección contra los tres serogrupos del virus vacunal antes de la vacunación y cómo fue modificada por esta, con una inmunidad superior al $80 \%$ para los virus 1 y 2 y de $76,7 \%$ para el virus tipo 3, en niños mayores de 1 año, tanto en área urbana como rural (Ferrer, Más Lago, 1967; Tejas et al., 1994; Tejas, 1995; Ochoa, Más Lago, 1987. 
El impacto de esta campaña de vacunación fue muy importante, ya que a los cuatro meses después de iniciada no se presentaron más casos de la enfermedad; en ese año 1962 solo se reportaron 46 casos en el primer semestre (Más Lago, 1995). Después de esa primera campaña se reportó solo un caso de poliomielitis aislado en los años 1963, 1964, 1970, 1971 y 1972 respectivamente y desde mayo de 1962 no se reportó ningún caso de mortalidad por su causa, según los datos de la Dirección Nacional de Estadísticas (Beldarraín Chaple, 2005).

La campaña de vacunación fue realmente un esfuerzo multidisciplinario, donde actuaron coordinadamente varias instituciones estatales y de masas, sin cuyo accionar no se hubiera obtenido un resultado tan efectivo. Asimismo, fue de importancia trascendental la participación popular, por primera vez en la historia del país, en la obtención de una meta relacionada con la salud de la población (Beldarraín Chaple, 2005).

\section{Principales resultados de la Campaña Nacional de Vacunación Antipoliomielítica}

Los principales resultados de la Campaña Nacional de Vacunación Antipoliomielítica se resumen en los siguientes:

- el objetivo de la campaña de vacunación antipolio por vía oral se cumplió ampliamente, con la vacunación del $87.5 \%$ de la población de 1 mes a 14 años de edad, con un rendimiento del 109.4\% de lo programado, con cinco millones de dosis aplicadas;

- quedó demostrada la efectividad de la participación de la población en campañas de este tipo, mediante la adecuada orientación a las organizaciones de masas en el orden técnico;

- el rendimiento del programa fue satisfactorio en todos los grupos de edades. El más bajo porcentaje se obtuvo en el grupo de 1 a 5 años de edad (Tabla 5);

- después de finalizada la campaña de vacunación, la incidencia de poliomielitis se encontró por debajo de la variación habitual (entre los años 1958 y 1961 se presentaron 64 casos en enero; 81 en febrero; 94 en marzo y 90 en abril, respectivamente, y en mayo se presentaron solo dos casos);

- los resultados obtenidos demostraron la efectividad de la utilización de dos dosis de vacuna trivalente con un millón de $\mathrm{DICT}_{50}$ para la protección contra la poliomielitis de la población infantil cubana;

- durante el desarrollo de la campaña no se observaron reacciones adversas graves atribuibles a la vacuna;

- la mortalidad por la enfermedad se eliminó desde el propio año que se inició la campaña de vacunación.

\section{Repercusión de la primera campaña nacional de vacunación antipoliomielítica y perfeccionamiento de las campañas siguientes}

La incidencia de la enfermedad se redujo a cero desde el año 1963 (solo se reportó un caso aislado en los años 1963, 1964, 1970, 1971 y 1972) y no hubo más mortalidad por la misma desde 1962. Este resultado fue un orgullo para el Sistema Nacional de Salud y sus profesionales, además de un modelo para los países del área y los organismos internacionales pusieron de 
ejemplo el desarrollo de la campaña cubana y su impacto. Los resultados de la campaña inicial de vacunación antipoliomielítica y su posterior desarrollo anual se reflejaron en el informe que el Ministerio de Salud Pública sometió a la OMS/OPS para solicitar la certificación de enfermedad eliminada del país, hecho este que se declaró oficialmente desde el 7 de noviembre de 1994, por dichos organismos internacionales (Tejas et al., 1994).

A partir de la fecha de la primera campaña de vacunación descrita (año 1962), en los años siguientes se realizaron ininterrumpidamente 34 campañas de vacunación antipoliomielítica (hasta 1994, lapso que incluye este estudio) que cubren todo el territorio nacional. Se mantuvo su aplicación en las semanas nacionales de vacunación en febrero y marzo, para los grupos de edades comprendidos entre 1 mes de nacidos y los 14 años. Se utilizaron diversos tipos de vacuna oral, la de mayor frecuencia empleada fue la Trivalente I - II - III (en los años 1962, de 1964 al 1967 y de 1969 a 1994); en 1963 se usó para la primera dosis Bivalente I - II, Monovalente I para la segunda dosis y en 1968 una Monovalente I en la primera dosis y Bivalente II - III para la segunda; estas decisiones estuvieron siempre respaldadas por la vigilancia epidemiológica de los virus circulantes basados en estudios virológicos (Tejas et al., 1994; Tejas, 1995). Hasta el presente, se mantiene en ellas la participación popular y activa de la comunidad a través de las organizaciones de masas, los CDR acompañados por la FMC que movilizan a los niños; se han incorporado los Médicos y Enfermeras de la Familia, pero siempre bajo el liderazgo técnico del Minsap y jerárquico de la máxima dirección del gobierno.

En algunos países de América, que emplearon estrategias para controlar y tratar de eliminar la poliomielitis, dividieron sus campañas de vacunación en etapas o fases de "captura" y de "mantenimiento"; también las bautizaron como "Jornadas Nacionales de Vacunación". Estas expresiones no son aplicables a la campaña cubana, que tuvo otra concepción.

Otros países introdujeron diseños propios, de acuerdo a sus realidades, por ejemplo en Costa Rica se aplicó la vacuna Salk desde 1956, aunque no de forma generalizada, pues el gobierno de los EEUU le asignó una cuota de 148 mil cc a dicho país, lo cual obligó a definir un rango etario para aplicarla, aparte de que el gobierno costarricense tuvo que comprometerse a que la vacuna se distribuyera a través de sus programas de salud y no por comercialización

Tabla 5: Rendimiento del Programa Vacunación

Antipoliomielítica por Provincias de Cuba, 1962

\begin{tabular}{lrrr}
\hline PROVINCIAS & \multicolumn{3}{c}{ VACUNACIONES } \\
\cline { 2 - 4 } & PROGRAMADAS & $\begin{array}{c}\text { EFECTUADAS } \\
\text { (dos dosis) }\end{array}$ \\
\hline Pinar del Río & 173.124 & 189.900 & 109,7 \\
Habana & 383.116 & 459.201 & 119,8 \\
Matanzas & 131.840 & 134.570 & 102,1 \\
Las Villas & 355.224 & 357.156 & 100,5 \\
Camagüey & 207.649 & 232.397 & 111,9 \\
Oriente & 748.832 & 814.631 & 108,8 \\
Cuba & 1.999 .785 & 2.187 .855 & 109,4 \\
\hline
\end{tabular}

Fuente: Datos del Departamento de Estadística del Minsap (Vacunación..., 1962). 
privada. Las dosis adquiridas no alcanzaban para cubrir a toda la población, de la cual la prioritaria fue la que aún no había nacido para la gran epidemia de 1954 y por tanto no había tenido la posibilidad de desarrollar inmunidad. Años después, en la década de 1960, hicieron campañas masivas en que cubrieron a toda la población infantil. Pero no pudieron erradicar la enfermedad hasta 17 años después de iniciar la vacunación (Malavassi Aguilar, 2012, p.115-117). Y si comparamos con un país europeo como España, donde se inició la vacunación en 1958 con vacuna Salk, administrada en tres dosis inyectables, antes del inicio de la misma se establecieron tres grupos (de beneficencia, débiles económicos y pudientes) para aplicar las diferentes tasas de vacunación: gratuita, pago de tres y de nueve pesetas por dosis. Se iniciaron campañas de vacunación masiva, pero pronto se confrontaron dificultades para mantenerlas a pesar de que en un principio se habían apoyado en un importante despliegue de medios para llegar a cada rincón urbano y rural. Fue necesario un cambio de estrategia: se disminuyó drásticamente el rango de la población a vacunar, se limitaron en el tiempo la secuencia y duración las fases de cada campaña, se disminuyó la inversión en infraestructura sanitaria móvil sin aumentar los recursos permanentes y se redujo la publicidad. Entonces, en la primavera de 1967, se implantaron dos campañas anuales de vacunación: en otoño y primavera. Tras efectuar el estudio serológico de un grupo de niños vacunados con dos dosis de vacuna oral trivalente, se juzgó necesario recomendar la administración de la tercera dosis a todos los vacunados previamente para completar la inmunidad. Como consecuencia hubo una cierta disminución en el número de casos en la segunda mitad de 1967 y a lo largo de 1968 (Porras, Báguenas, 2013, p.145-166).

En Cuba han variado los esquemas relacionados con las edades de la población infantil a vacunar. De acuerdo con los resultados de estudios serológicos de inmunidad, se produjo la disminución paulatina de las edades a vacunar. En la actualidad, la primera dosis la reciben los niños desde 30 días de nacidos hasta los 2 años, 11 meses y 29 días y la segunda dosis a este grupo etario además de la reactivación a los niños de 9 años (desde los 9 hasta 9 años, 11 meses y 29 días). Durante la segunda campaña, en dos oportunidades, se modificó el tipo de vacuna como resultado de la evaluación serológica. Se modificó la distribución de los virus en la vacuna, como se explicó en párrafo precedente (Tejas et al., 1994; Cabrera, 5 mar. 2012).

En la tercera campaña (correspondiente a 1964), para garantizar el nivel óptimo de la inmunidad en las edades de mayor riesgo, se utilizó una modalidad de vacuna que contenía un millón de DICT $_{50}$ para cada uno de los tres serogrupos (Del Puerto, Ferrer, Toledo, 2002). Desde 1970 a 1991 se utilizó una vacuna que contenía las DICT $_{50}$ siguientes: quinientos mil, doscientos mil y trescientos mil para los tipos 1, 2 y 3 respectivamente (Ochoa, Más Lago, 1987; Tejas et al., 1994).

Desde 1992 la vacuna se presenta en gotas y no en grageas. Aún se mantiene el sistema de campañas masivas, las cuales prácticamente se efectúan en 72 horas, con una cobertura superior al 90\%. Desde 1970 hasta 1992 el esquema consistió en dos dosis de vacuna trivalente para la población infantil de hasta 3 años con intervalo de seis semanas y una dosis de reactivación a los niños de 9 años (Tejas, 1995). También se han incorporado al trabajo de la campaña el médico y la enfermera de la familia y se han usado diferentes vacunas. Es decir, se ha perfeccionado técnicamente la campaña de vacunación, sobre la base de la experiencia que han ganado las organizaciones de masas que intervienen en la misma, la involucración 
activa de la atención primaria de salud con su última estructura del médico y enfermera de la familia (Tejas, 1995), así como las modificaciones, tanto en la composición de las vacunas y su presentación como en la educación sanitaria relacionada con la protección de la enfermedad que alcanzó la población cubana, lo que ha permitido mantener al país libre de la presencia de la enfermedad.

Otro aspecto científico de trascendental importancia relacionado con la introducción de la vacunación antipoliomielítica fue el inicio y desarrollo posterior de los estudios virológicos en el país, iniciados por el doctor Pedro Más Lago. El asesor técnico de la campaña, profesor Karel Sacek, realizó también las primeras evaluaciones serológicas y dio orientaciones con vistas a establecer un sistema de vigilancia (Más Lago, 1995).

Se creó un laboratorio de investigaciones virológicas, que tenía funciones del sistema de vigilancia y también de asesorar científicamente al programa de vacunación. Este laboratorio mantuvo una vigilancia anual de la inmunidad de la población infantil mediante encuestas serológicas y recomendaba los grupos de edad y tipo de vacuna a utilizar. Se efectuaron más de veinte encuestas serológicas para investigar la inmunidad a los tres tipos de poliovirus, dos de las cuales se realizaron con ayuda financiera de la OPS (Tejas et al., 1994).

\section{La eliminacion de la poliomielitis en Cuba}

Con la primera campaña de vacunación antipoliomielítica, efectuada en 1962, se ganó la batalla inicial contra la enfermedad, pues ya en el segundo semestre del año no se presentaron casos nuevos y la mortalidad se eliminó totalmente, pero era necesario mantener este logro. Para ello se decidió repetir las campañas de vacunación, todos los años, a los mismos grupos de edades y en las mismas fechas.

Entre 1962, año en que se inició la vacunación, y 1994, en que se solicitó la certificación internacional de eliminación, se aplicaron en el país 62.544.458 dosis de vacuna, lo que garantizó que toda la población cubana, menor de 49 años, tuviera una cobertura superior al 90\% con la vacuna antipolio (Más Lago, 1995; Más Lago et al., 2008).

Esto fue posible debido al cambio de paradigma que se aplicó en el sector salud después del $1^{\circ}$ de enero de 1959, que ya se mencionó en párrafos anteriores, en que se privilegió la prevención de enfermedades sobre la curación de las mismas, sin dejar de lado esto último, iniciando grandes campañas epidemiológicas. Estas transformaciones comenzaron a la vez que la reforma de salud culminó con un sistema de salud único, gratuito y de cobertura nacional que se ha modificado permanentemente a través de los años. Esto demuestra la importancia de la voluntad política para resolver los problemas sanitarios de la población.

A lo largo de estos años, las campañas han contado con la colaboración de diversos organismos internacionales como OPS, OMS, Unicef y el Club Rotario Internacional, que aportaron ayuda técnica a través de la participación de expertos para la asesoría y superación de los profesionales que participarían en las mismas, suministraron equipos, desde vehículos hasta los termos para el transporte refrigerado de las vacunas, así como las vacunas mismas.

Cuando comenzó el Programa Nacional de Vacunación Antipoliomielítica en 1962, se creó una Comisión Nacional para el Estudio de los Síndromes Neurológicos Infecciosos, formada por neurólogos, virólogos, pediatras y epidemiólogos, encargada de investigar todos los casos 
sospechosos de poliomielitis. Entre 1963 y 1989 esta comisión analizó 93 casos sospechosos y en sus conclusiones comprobó diez casos de poliomielitis, todos en niños no vacunados. En 15 casos se aislaron enterovirus no poliomielíticos y los 68 restantes se diagnosticaron como síndrome de Guillain Barré, mielitis transversa y otras polineuropatías (Más Lago, 1995; Tejas et al., 1994).

La parálisis fláccida está reportada como evento adverso a la vacunación con OPV en Cuba (Más Lago et al., 2008). Galindo y colaboradores refieren veinte casos reportados de parálisis fláccida relacionada con la vacunación (el último en 2006) y reconocen que es una complicación rara; para la población total vacunada, menor de 15 años en Cuba, en el período comprendido entre 1962 y 2006 representó un riesgo de 1/3 de 778.811 por dosis aplicada (Galindo et al., 2012).

En los controles de foco realizados entre 1963 y 1989, las medidas de control principales que se tomaron fueron la confección de las historias epidemiológicas, tomas de muestras de heces fecales para estudios virológicos, los estudios serológicos (sueros pareados) y el estudio virológico del material obtenido en las necropsias de los niños fallecidos con sospecha de poliomielitis, estudiados por la Comisión Nacional de Síndromes Neurológicos Infecciosos (Tejas et al., 1994).

Desde 1967 se sospechó la interrupción de la circulación del virus salvaje y se planteó la necesidad de realizar investigaciones para verificarla. Desde 1970 a 1994 se diseñaron y ejecutaron más de seis investigaciones con estos fines, todas con resultados negativos (Más Lago et al., 1994; Tejas et al., 1994). Se investigó la regresión de la atenuación del virus vacunal al multiplicarse en el intestino, el paso transplacentario de los anticuerpos inducidos por la vacuna, la duración de la inmunidad y la seroconversión conferida con distintas dosis.

La poliomielitis se pudo eliminar de Cuba gracias a la combinación permanente de varios elementos, como fueron: mantener una alta cobertura de inmunización; un sistema de vigilancia epidemiológica de alta sensibilidad, que incluía un estudio exhaustivo de cada caso sospechoso de poliomielitis realizado por la Comisión Nacional de Síndromes Neurológicos Infecciosos; un compromiso político sostenido; un alto grado de participación social y una comunicación social constante y efectiva (Vacunación..., 1962; Del Puerto, Ferrer, Toledo, 2002; Tejas et al., 1994; Tejas, 1995).

Si la poliomielitis hubiese seguido su ciclo natural, sin ser este interrumpido por la vacunación, entre 1962 y 1970 debieron haberse presentado 1.200 casos de parálisis y doscientos defunciones, como calculó el doctor Más Lago (1995). La eliminación de la enfermedad indudablemente demostró el impacto de la vacunación sistemática, por campañas, llevada a cabo en Cuba.

El propio doctor Sabin, quien visitó Cuba en 1967, comprobó, desde el inicio, los éxitos alcanzados. El país demostró que con una estrategia, como la llevada a cabo (única en el mundo hasta ese momento), era posible eliminar la poliomielitis con una vacuna oral de virus vivos atenuados, a pesar de la poca efectividad que para las naciones tropicales se reportaba en la literatura. Otra de las ventajas que reporta hacer una campaña al unísono en todo el país y en solo dos momentos en el año, es que se evita la diseminación constante de virus vacunal al ambiente (Más Lago et al., 1994). 
La campaña de vacunación masiva fue una estrategia que adoptaron después algunos países, incluso fue recomendada por la OPS, pero en esta estrategia Cuba fue pionera con la conjugación del empleo de la ciencia, la voluntad política y la participación popular, ejemplo a seguir por otros países de la región o fuera de ella (Roses, 1995; González, 1995).

La Organización Panamericana de la Salud emitió la Certificación de Erradicación de la enfermedad en 1994, mediante una nota firmada por su director, doctor Carlyle Guerra de Macedo (OPS, 1995).

Durante el análisis del informe presentado por Cuba el 8 de junio de 1994 para obtener dicho certificado (OPS, 1995), el jefe del Programa de Inmunizaciones de la OPS, doctor Ciro de Quadros, calificó la estrategia de vacunación empleada en esta campaña como un modelo a imitar para el resto del mundo.

En el acto de entrega de dicha certificación, la doctora Mirta Roses, directora asistente de la OPS, en esos momentos, al referirse a la Primera Campaña de Vacunación dijo: "Su concepción, su ideología, sus instrumentos, su metodología, sacudieron al mundo. Cuba sentó las bases imprescindibles para que se encendiera la gran chispa, Cuba transformó lo probable en posible" (Roses, 1995, p.7).

\section{Consideraciones finales}

La Primera Campaña de Vacunación Antipoliomielítica fue uno de los primeros logros de la medicina preventiva y de la epidemiología cubana después del inicio de la reforma del sistema de salud en 1959. La estrategia desarrollada y mantenida, con sus resultados de eliminación de la enfermedad, desde la segunda mitad de 1962, permitió finalmente la obtención del Certificado Internacional de Eliminación de esta enfermedad, otorgado por la OMS en 1994.

Se planificó una campaña con cobertura nacional que se puso en práctica en los primeros meses de 1962. Consistió en el desarrollo de dos semanas nacionales de vacunación, a finales del mes de febrero y en abril, en las cuales se administró la primera y segunda dosis de vacuna oral tipo Sabin, respectivamente, a toda la población infantil del país menor de 15 años. En esta campaña participaron, por primera vez en el país, las organizaciones de masas que agrupaban a los diversos sectores de la población, como organismos líderes en el trabajo de la vacunación, capacitados previamente por los especialistas del Ministerio de Salud Pública a diferentes instancias. El trabajo fue acompañado por los profesionales de salud de cada comunidad, así como asesorado y controlado por especialistas que componían las diversas estructuras territoriales del sector salud.

Las campañas se mantuvieron de forma similar durante el lapso de tiempo analizado, hasta 1994, cuando se desarrollaron 34 campañas de vacunación antipoliomielíticas. Actualmente se mantienen, han variado en algunas ocasiones los componentes antigénicos de la vacuna, según los resultados de la vigilancia epidemiológica en relación a la circulación viral en cada momento. Con el paso de los años y de acuerdo al estado inmunitario de la población infantil cubana en relación a los virus de la poliomielitis, se han hecho ajustes a las edades en que se aplica la vacuna.

La estrategia diferente que se usó en Cuba y sus resultados han sido de utilidad y ejemplo para otros países en su interés de programar actividades de eliminación de esta enfermedad. 
La experiencia de Cuba en la eliminación de la poliomielitis demuestra que cuando se dispone de una herramienta científica eficaz, como la vacuna, y se toman las medidas epidemiológicas adecuadas, unido a una voluntad política de las autoridades sanitarias y estatales, que permita movilizar todos los recursos disponibles tanto económicos como de personal, así como técnicos, es posible enfrentar el problema y controlarlo, aunque este sea de gran magnitud.

\section{AGRADECIMIENTOS}

El autor quiere agradecer por la ayuda brindada para esta investigación al DrC. Helenio Ferrer, así como a los fallecidos profesores DrC. Gabriel Toledo Curbelo y DrC. Conrado del Puerto Quintana, al Dr. Miguel Ángel Galindo Sardiñas, así como a los especialistas de la Dirección Nacional de Estadísticas del Minsap.

\section{NOTA}

${ }^{1}$ Es la dosis mínima del microorganismo que puede ocasionar enfermedad. Cuando se le administra a la persona vacunada es la que produce la inmunidad específica contra dicho agente patógeno.

\section{REFERENCIAS}

BELDARRAÍN CHAPLE, Enrique.

Apuntes para la historia de la sanidad en Cuba. Revista Finlay, v.12, n.1, p.17-19. 2007.

BELDARRAÍN CHAPLE, Enrique.

Apuntes sobre la Medicina en Cuba: historia y publicaciones. La Habana: Editorial Ciencias Médicas. 2005.

CABRERA, Marieta.

Nueva campaña de vacunación antipolio. Bohemia, año 104. Disponible en: http://www. bohemia.cu/2012/03/05/nacionales/nuevacampana-de-vacunacion-antipolio.html. Acceso en: 5 jul. 2012. 5 mar. 2012.

CDC.

Centers for Disease Control and Prevention. International notes certification of poliomyelitis eradication - the Americas, 1994. Morbidity and Mortality Weekly Report, v.43, n.39, p.720-722. 1994

CDC.

Centers for Disease Control and Prevention. Update: polio eradication - the Americas, 1993. Morbidity and Mortality Weekly Report, v.42, n.35, p.685-686. 1993.

CUBA.

Ministerio de Salud Pública. Departamento de Estadísticas. Libros de Registros de Incidencia, años 1959 a 1961. La Habana: Dirección de Registros Médicos. s.d.

DELGADO, Gregorio.

Conferencias de historia de la administración de Salud Pública en Cuba. Cuaderno de Historia de la Salud Pública, n.81, p.81-98. 1991.
DEL PUERTO, Conrado; FERRER, Helenio; TOLEDO, Gabriel.

Higiene y epidemiología, apuntes para su historia. La Habana: Editorial Palacio de las Convenciones. 2002 .

FERRER, Helenio.

Comunicación personal. jun. 2008.

FERRER, Helenio; MÁs LAGO, Pedro.

Estado actual de la campaña de erradicación de la poliomielitis en Cuba. Boletín de Higiene y Epidemiología, v.5, n.2, p.145 -155. 1967.

GALINDO, Belkis et al.

Vaccine-related adverse events in cuban children, 1999-2008. MEDICC Review, v.14, n.1, p. 38-43. 2012.

GONZÁLEZ, Rodrigo.

Discurso del representante del Rotary

International, The Rotary Foundation. Boletín del Ateneo Juan César García, v.3, n.1-2, p.9-10. 1995.

HARRIES, Her; MITMAN, Maurice.

Poliomyelitis clinical practice in infectious diseases. Edinbourgh: E \& S Livingstone. 1951.

HERNÁNDEZ SAMPIERI, Roberto; FERNÁNDEZ COLLADO, Carlos; BAPTISTA LUCIO, Pilar. Metodología de la investigación. Bogotá: McGraw Hill. 1996.

HEYMANN, David (Ed.).

El control de las enfermedades transmisibles. Washington, DC: OPS/OMS. 2005.

INSTITUTO...

Instituto de Historia de Cuba. La neocolonia: 
organización y crisis, desde 1899 hasta 1940 . La Habana: Editora Política. 1998.

MALAVASSI AGUILAR, Ana Paulina.

Análisis de las percepciones de un grupo de estudiantes de pedagogía de la Universidad de Costa Rica sobre la poliomielitis, la víctima y la rehabilitación: Casa Verde, 1955-1957. In: Díaz Arias, David (Ed.). Historia de la infancia en la Costa Rica del siglo XX. San José: Editorial Nuevas Perspectivas. p. 93-153. 2012.

MARTÍNEZ-FORTÚN, José Andrés.

Epidemiología en Cuba republicana y con especial referencia a la poliomielitis aguda. Revista de la Sociedad Cubana de Historia de la Medicina, v.3, n.3, p.3-10. 1960.

MARTÍNEZ-FORTÚN, José Andrés.

Epidemiología (síntesis cronológica). Cuadernos de Historia Sanitaria, n.5, p.78-112. 1952.

MÁs LAGO, Pedro.

Impacto social de la vacunación antipoliomielítica en Cuba. Boletín del Ateneo Juan César García, v.3, n.1-2, p.13-21. 1995.

MÁS LAGO, Pedro et al.

Casos de poliomielitis paralítica asociada a la vacuna oral antipoliomielítica en Cuba (19632006). Revista Cubana de Higiene y Epidemiología, v.46, n.2, p.1-14. 2008.

MÁS LAGO, Pedro et al.

Lecciones desde Cuba: administración de vacuna antipoliomielítica oral trivalente en campañas masivas y seroprevalencia de anticuerpos neutralizadores de los poliovirus. Bulletin of the World Health Organization, v.72, n.2, p.221-225. 1994.

OCHOA, Edilberto; MÁS LAGO, Pedro. Epidemiological surveillance and control of poliomyelitis in the Republic of Cuba. Journal of Hygiene Epidemiolgy, Microbiology and Immunology, v.31, n.4, p.381-389. 1987.

OPS.

Organización Panamericana de la Salud. Certificación de la erradicación de la poliomielitis. Boletín del Ateneo Juan César García, v.3, n.1-2, p.1. 1995.

\section{PAHO.}

Pan American Health Organization. Polio: the beginning of the end. Statement by Dr. David Brandling-Bennett, Deputy Director, PAHO, at Polio Eradication: The Opportunity of a Lifetime event. Washington, DC. 12 abr. 2000.
PORRAS, María Isabel; BÁGUENAS, María José. La lucha contra la enfermedad mediante las campañas de vacunación en Madrid, Valencia y Castilla: La Mancha (1958-1975). In: Porras Gallo, María Isabel et al. (Coord.). El drama de la polio, un problema social y familiar en la España franquista. Madrid: Libros de la Catarata. p.141169. 2013.

QUADROS, Ciro A. de; HERSH, Bradley S.; OLIVÉ Jean-Marc.

Eradication of wild poliovirus from the Americas: acute flaccid paralysis surveillance. Journal of Infectious Diseases, v.175, suppl.1, p.S37-42. 1997.

RECIO, Alberto.

Tres casos de poliomielitis anterior aguda. Revista Médica Cubana, t.14, n.2, p.66-74. 1909.

ROBBINS, Frederick C.; QUADROS, Ciro A. de. Certification of the eradication of indigenous transmission of wild poliovirus in the Americas. Journal of Infectious Diseases, v.175, suppl.1, p.S281-285. 1997.

ROJAS OCHOA, Francisco; LÓPEZ SERRANO, Elena.

Revolución social y reforma sanitaria, Cuba en la década de los 60. In: OPS. Concursos regionales reforma sanitaria en perspectiva histórica. Washington, DC: OPS. 2002.

ROSES, Mirtha.

Discurso pronunciado en el acto de entrega de la certificación de erradicación de la poliomielitis en Cuba. Boletín del Ateneo Juan César García, v.3, n.1-2, p.7-8. 1995.

TEJAS, Julio.

Discurso del ministro de Salud Pública de Cuba. Boletín del Ateneo Juan Cesar García, v.3, n.1- 2, p.4-6. 1995.

TEJAS, Julio et al.

Informe preliminar del Ministerio de Salud Pública de Cuba para optar por el "Certificado de Erradicación de la Poliomielitis" en el continente americano. La Habana: Minsap. mayo 1994.

US DEPARTMENT...

U.S. Department of Health and Human Services/ Centers for Disease Control and Prevention. Polio vaccine information statement. National immunization program. Washington, DC. 2000.

VACUNACIÓN...

Vacunación antipoliomielítica en Cuba. Tribuna Médica Cubana, n.470-475, p.16-27. 1962.

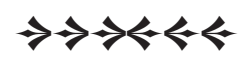

